\title{
The possible protective role of omega 3 on liver of $L$ thyroxine treated male albino rats. Histological and immunhistochemical study
}

\section{Original Article}

\author{
Fatma Yassine Meligy', Ola A. Hussein ${ }^{1}$, Heba A.E.Mubarak', Mohamed M. Abdel \\ - daim $^{2}$ \\ ${ }^{1}$ Histology and cell biology Department, Faculty of Medicine, Assiut University, Assiut, \\ ${ }^{2}$ Pharmacology department, Faculty of veterinary medicine, Suez canal university, Egypt
}

\begin{abstract}
Background: Hyperthyroidism is a condition associated with oxidative damage of liver. Omega-3 fatty acids are effective in various medical conditions due to antioxidant, anti-inflammatory, anti-apoptotic and anti-fibrotic activities.

Aim of the work: Here we evaluate the potential effects of omega-3 fatty acids on experimentally induced hyperthyroidism. Materials and methods: Thirty adult male rats were divided equally into 3 groups; Control group (G1) received saline. Hyperthyroid (GII) received L-thyroxine group $0.1 \mu \mathrm{g} / \mathrm{g} /$ day intraperitoneal for 6 weeks. L-thyroxine+Omega-3 group (GIII) received L-thyoxine as previous group then $12 \%$ of eicosapentaenoic acid (EPA), and 18\% of docosahexaenoic acid (DHA) for 4 weeks (from 3rd to 6th weeks). Blood samples were taken for detection of liver enzymes, serum T3 and TSH. Liver samples were taken for light and electron microscopic examination. Immunohistochemical staining of CD68, Caspase 3 and proliferating cell nuclear antigen (PCNA) were done.

Results: L-thyroxine over dose decreased TSH, increased serum T3 and liver enzymes (ALT \&AST). Also, it induced patches of cytoplasmic vacuolation, dense nuclei, vascular congestion and significant increase of collagen fibers. Electron microscopic changes revealed rarified cytoplasm and mitochondria with destructed cristae in most hepatocytes, . Significant increase of caspase 3 and CD68 immunoexpression and significant decrease of (PCNA) immunoexpression were noticed. Concomitant treatment with omega 3 showed decreased liver enzymes and T3. Improvement of most morphological alterations in the hepatocytes was observed. Significant decrease of collagen fibers, caspase 3 and CD68 immunoexpression was observed and significant increase of PCNA immunoexpression.
\end{abstract}

Conclusion: Combined treatment with omega 3 ameliorated most of L. thyroxine induced liver changes and serological parameters.

Received: 16 Jan 2019, Accepted: 22 Mar 2019

Key Words: Hyperthyroidism, immunohistochemistry, liver, omega3.

Corresponding Author: Fatma Yassine Meligy, MD, Histology and cell biology Department, Faculty of Medicine, Assiut University, Assiut, Egypt, Tel.: +2 01021900608, E-mail: fmeligy@gmail.com.

ISSN: 2536-9172, Dec 2018 Vol.2, No.2

\section{INTRODUCTION}

The liver has important functions in human body including lipids and carbohydrates metabolism, production of hormones and clotting factors, and detoxification $^{[1-2]}$. Hormones of thyroid gland have an important role in development and growth of almost body tissues and organ system ${ }^{[3]}$ including liver by controlling normal hepatic function,structure and normal bilirubin metabolism ${ }^{[4-5]}$. Hyperthyroidism is a condition associated with overproduction and secretion of thyroid hormones, which causes thyrotoxicosis with oxidative damage of liver ${ }^{[6]}$,so liver dysfunction is reported in $37 \%$ to $77.9 \%$ of patients with hyperthyroidism of previous studies ${ }^{[7]}$. In addition abnormalities of biochemical markers of liver as the alanine aminotransferase (ALT) and aspartate aminotransferase (AST) levels (transaminases) usually are associated with inflammation and/or injury to liver cells including hyperthyroidism cases $^{[8]}$. The possible mechanism between hyperthyroidism and hepatic dysfunction is unclear ${ }^{[9]}$. Previous study has found that the harmful reactive oxygen species (ROS) production was stimulated by excess thyroid hormones ${ }^{[10]}$. Recent studies reported that oxidative stress and mitochondrial oxygen consumption increased in hyperthyroid rat liver ${ }^{[1]]}$. It has been found that antioxidants like vitamin $\mathrm{E}$ and curcumin, had a protective role against L-thyroxine induced hepatic dysfunction and oxidative stress ${ }^{[12]}$.Treatments that can protect liver function and prevent hepatic damage are still rare as most clinical treatment of hyperthyroidism induced hepatic damage is mainly to control clinical symptoms of hyperthyroidism ${ }^{[7]}$. So, new treatments discovery which has the property of both hepatoprotective and antithyroid efficacy will be very helpful.

Omega-3 polyunsaturated fatty acids (PUFAs) are long 
chain PUFAs found in marine sources as shrimp, fish, mussel, oyster, ${ }^{[13]}$, nuts and sesame seeds ${ }^{[14]}$, flax seed and vegetable oils such as soybean, canola and olive ${ }^{[15]}$. It has been found that the benefits of Omega-3 (PUFAs) could be due to reduction in the production of pro-inflammatory cytokines, act as antioxidant and immune system protection $^{[16]}$. The protective health effects of omega-3 fatty acids were described first in the Greenland Eskimos who consumed a high seafood diet and had low rates of coronary heart disease, asthma, type 1 diabetes mellitus, and multiple sclerosis ${ }^{[17]}$. Also, the beneficial health effects of omega-3 fatty acids include cancer, inflammatory bowel disease, rheumatoid arthritis, and psoriasis ${ }^{[18]}$.

\section{AIM OF THE WORK}

Owing to insufficient research work done to evaluate hyperthyroidism related liver damage. The present work aimed at investigating the possible protective role of omega 3 on $\mathrm{L}$ thyroxine overdose induced hepatic structural and functional changes in adult male albino in relation to different immunohistochemical markers.

\section{MATERIALS AND METHODS}

\section{I) Experimental design:}

Adult male Wister Albino rats weighing $180-200$ gm were used for this study. Animals were housed in clean capacious cages (4 rats per cage) in Animal House of Faculty of Medicine, Assiut University. They will be maintained on a natural 12:12-h light-dark cycle in well aerated room, temperature $\left(25 \pm 5{ }^{\circ} \mathrm{C}\right.$ ), food (standard rat pellets) and water available ad libitum. Before the experiment, the animals will be habituated to handling and the testing environments for four days. The experimental procedures were carried out according to "Guidelines of Experiments on Animals" at Faculty of Medicine, Assiut University, Egypt.

\section{- Animal groups}

30 rats in the present study were randomly divided into the following groups:

Group I: 10 rats served as control group and received saline.

Group II: 10 rats served as Hyperthyroid treated group received L-thyroxine at a dose of $0.1 \mu \mathrm{g} / \mathrm{g} / \mathrm{day}$ (SigmaAldrich, USA) intraperitoneal for 6 weeks ${ }^{[19]}$

Group III: 10 rats are considered as hyperthyroid as group II then received omega 3 after confirming hyperthyroidism by serological tests had been established at the end of the second week for 4 weeks. They were fed a chow diet and supplemented daily with $3.0 \mathrm{~g} / \mathrm{kg}$ animal weight of an oral compound containing $12 \%$ of (eicosapentaenoic acid )EPA and 18\% of (docosahexaenoic acid)DHA ${ }^{[20]}$.

At the end of the experiment, the animals were anesthetized with an intraperitoneal injection of thiopental sodium $(50 \mathrm{mg} / \mathrm{kg})$. Liver specimens were subjected to the following studies:

light microscopic study: The liver specimens were fixed in 10\% neutral formalin and processed to get paraffin sections $(5 \mu \mathrm{m})$ stained with haematoxylin and Eosin(Hx\&E), Masson's trichrome and PAS ${ }^{[21]}$

\section{Immunohistochemistry}

After fixation in 10\% neutral formalin for 2 days, dehydration, clearing and embedding. Paraffin sections were cut at 4 um and stained with modified avidin-biotin peroxidase technique. Sections were deparaffinized and rehydrated. Then, slides were incubated in $0.3 \%$ $\mathrm{H} 2 \mathrm{O} 2$ for 10 minutes to abolish endogenous peroxidase activity. The tissue sections were incubated overnight at room temperature with the following primary antibodies: anti-caspase-3 [mouse monoclonal antibody (Lab Vision, Fremont, CA USA), antiprimary antibodies to proliferating cell nuclear antigen (PCNA) (Clone PC 10; Dako Denmark A/S, Glostrup, Denmark) and monoclonal mouse antiCD68 for detection of macrophages(Sigma-Aldrich Inc., St Louis, MO, USA) at dilutions of 1/100-400, then washed with PBS and incubated with biotinylated secondary antibodies and then with avidin-biotin enzyme complex. The immunoreactivity was visualized

using 3, 30- diaminobenzidine hydrogen peroxide as a chromogen.

The sections were finally counterstained with Mayer's hematoxylin.

Negative control slides were done with omission of the primary antibodies using non immunized goat sera. Positive controls were done for all antibodies used respectively (tonsil, skin and tonsil) ${ }^{[23]}$.

E.M. Study: Animals from each group were perfused intracardially with $4 \%$ cold glutaraldehyde in cacodylate buffer (PH7.4). Specimens (1mm) size were taken from liver and processed. Ultrathin section $(500 \mathrm{~A})$ were cut form the selected areas in semithin section, and studied with transmission electron microscope. JEOL (J.E.M.-100 CXII) and photographed at $80 \mathrm{~K} . \mathrm{V}$ in Assiut University / Electron Microscope Unit ${ }^{[22]}$

\section{Morphometric study}

Three non overlapped fields in each of five sections of each of 3 rats from each group were used for measuring the following: 
1. The number of positive PCNA immunostained nuclei were counted in 3 nonoverlapping fields in each section X400

2. The number of positive CD68 immunostained cells were counted in 3 nonoverlapping fields in each section X400

3. The area \%of distribution of collagen fibers in 3 Mallory trichrome stained nonoverlapping sections (X100)

All morphometric studies were done by using image $\mathrm{J}$ which is a Java based open source image processing package.

\section{Statistical analysis}

The morphometric data, expressed as mean $\pm \mathrm{SD}$, of each group were statistically analyzed using SPSS (version 16; SAS Institute Inc., Cary, North Carolina, USA). The independent ANOVA test was used to compare the animal groups. $\mathrm{P}$ value less than 0.05 was considered significan ${ }^{[24]}$.

\section{Serological Study}

Measurement of serum triiodo-L-thyronine (T3) and thyroid stimulating hormone (TSH):

Enzyme-linked immunosorbent assays (ELISA) commercial kits (BioSource, Belgium, Europe) were used to measure the levels of both T3 and TSH in the serum of the three rat groups, following the instructions attached with each kit.

Measurement of serum alanine transaminase (ALT) and aspartate transaminase aminotransferase (AST):

The serum levels both ALT and AST were assayed using commercial kits (Chema, Italy) using the manufacturer's instructions to determine their enzymatic activities with a spectrophotometric technique by the Olympus AU-2700 auto analyzer and presented as IU/L.

\section{RESULTS}

\section{A. Histological results}

\section{Light microscopic results:}

Light microscopic examination of H\&E stained sections of group I (control group) showed hepatocytes arranged in cords radiating from the central vein (Fig.1.a). They were polyhedral in shape with granular cytoplasm and vesicular large nuclei, liver cords were separated by blood sinusoids (Fig.1b). Examination of group II (L. thyroxine treated group) showed that liver changes were noted in the form of patches of cellular degeneration through the lobules (Fig.1c). Some of altered cells showed dense nuclei and vacuolated cytoplasm, others lost their nuclei (Fig.1c). There were patches of mononuclear cellular infiltrations (Fig.1d ). Congestion were observed in blood vessels (Fig.1c). In group III (L- thyroxine +Omega3 treated group), after administration of Omega-3 exhibited reduction in hepatic changes. Most of hepatocytes regained their nearly normal structure (Fig.1e).

Masson'strichrom stained sections of control group showed few collagenous fibers around the central vein (Fig.2a). While in (L- thyroxine treated) there was an extensive amount of collagen fibers around the central veins (Fig.2b) and in the portal areas. In group III, few collagen fibers were observed around the central vein (Fig.2c) and at portal tracts. Statistically, there was significant increase of collagen

area $\%$ in (L. thyroxine treated group) compared to control group and a significant decrease in (L.thyroxine +omega3 treated group) compared to group II (Fig.2d).

PAS stained sections of control group revealed that the cytoplasm of most of hepatocytes had a strong reaction (Fig.3a). L-treated group showed weak PAS reaction in multiple hepatocytes (Fig.3b). While after treatment with omega 3(group III), a strong PAS reaction could be seen in most of hepatocytes compared to group II (Fig.3c).

\section{Immunohistochemistry}

Immunostainning for CD68 of control group showed few +ve Kupfer cells scattered in the sinusoidal walls (Fig.4a). InL.thyroxine treated group, there was an increase in the scattered immunostained CD68 +ve cells(Fig.4b). While in L. Thyroxine +omega3 treated group, there was few scattered CD68+ve cells(Fig.4c). Immunostaining for cleaved caspase- 3 of control group showed few scattered cells in the liver lobule (Fig. 4d). In L. thyroxine treated group, there was a numerous caspase $3+$ ve cells(Fig. 4e). After treatment with omega3, there was fewer caspase 3 positive cells (Fig. 4f). Immunostaining for PCNA of control group showed multiple immunostained +ve cells (Fig.4g). In L. thyroxine treated group, there was marked decrease in PCNA+ve cells (Fig.4h) While after treatment with omeg3 there was multiple PCNA +ve cells (Fig.4i). Statistically there was significant increase of CD68 +ve cells in L. thyroxine treated group compared to control and significant decrease after treatment with omega3 compared to groupII (Fig. 4j). Also there was significant decrease in PCNA +ve cells in L.thyroxine treated group compared to control and a significant increase in immunostained cells in group III compared to group II (Fig.4k).

Electron microscopic examination of hepatocytes of control group showed large rounded euchromatic nuclei with prominent nucleoli. The cellular organelles were uniformly distributed throughout the cytoplasm. Numerous 
mitochondria, cisternae of rough endoplasmic reticulum, lipid droplets and numerous smooth endoplsmic reticulum were noted (Fig.5.a). Examination of L. thyroxine treated group revealed appearance of many electron lucent areas of the rarified cytoplasm and mitochondria with destructed cristae. The nuclei were variable in size and showed peripheral localization of heterochromatin clumps (Fig.5b).

Examination of group III revealed most of hepatocytes regained their normal structure, however few electronlucent areas were observed in the cytoplasm .The mitochondria seemed to be normal and apparent regular arrangement of rough endoplasmic reticulum (Fig. $5 \mathrm{c} \& d$ ).

\section{B. Serological results}

Increase in serum T3 and decrease in serum TSH levels were significantly observed after administration of L-thyroxine compared to the control group. After omega-3 administration, serum analysis of these hormones revealed significant decrease in T3 and a significant increase in TSH levels when compared to hyperthyroid group. Meanwhile, the level of T3 was significantly higher and the level of TSH was significantly lower in hyperthyroid omega-3 treated than the control (Table $1 \&$ Hitogram 1,2). serum levels of both ALT and AST were significantly higher in hyperthyroid animals when compared to control. Omega-3 treatment to hyperthyroid rats resulted in significant reduction of both ALT and AST in comparison with hyperthyroid rats. The levels of both ALT and AST were insignificant in hyperthyroid omega-3 treated group when compared with control group (Table 2 \& Histogram 3 ).

Table 1: Serum levels of triiodo-L-thyronine level (T3) and thyroid stimulating hormone (TSH)

\begin{tabular}{lccc}
\hline & Control & Hyperthyroid & Omega-3 treated \\
\hline $\mathrm{T} 3(\mathrm{ng} / \mathrm{dL})$ & $61.79 \pm 5.76$ & $356.31 \pm 16.39 *$ & $271.08 \pm 13.76^{*} \#$ \\
$\mathrm{TSH}(\mu \mathrm{IU} / \mathrm{mL})$ & $0.186 \pm 0.02$ & $0.061 \pm 0.01^{*}$ & $0.055 \pm 0.02 * \#$ \\
\hline
\end{tabular}

Note: Data are presented as means $\pm \mathrm{SD}(\mathrm{n}=8$ in each group).

* Statistically significant when compared to control group.

\# Statistically significant when compared to hyperthyroid group.

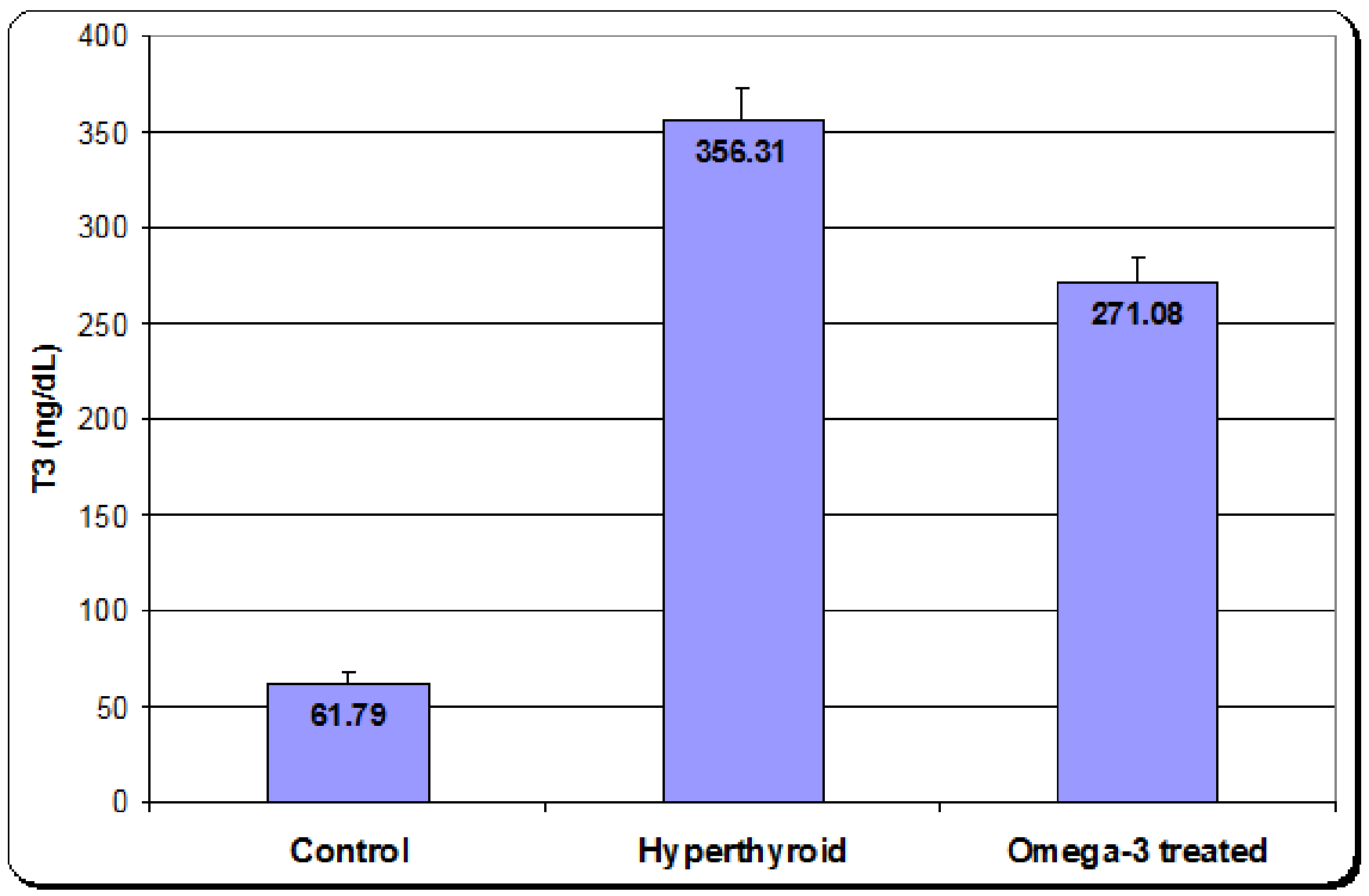

Histogram 1: Serum levels of T3 in different groups 


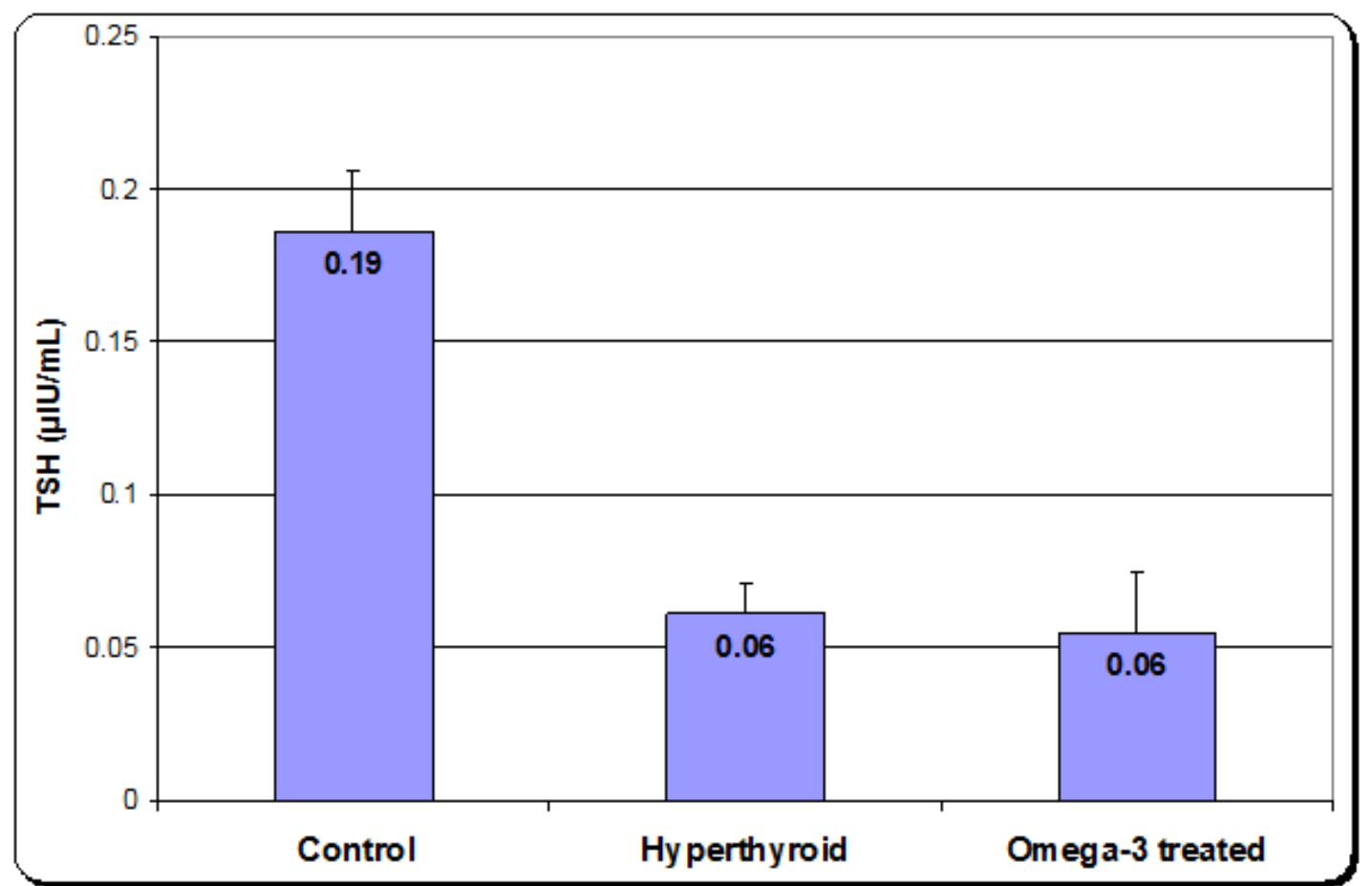

Histogram 2: Serum levels of TSH in different groups

Table 2: Serum Levels of alanine transaminase (ALT), aspartate transaminase (AST)

\begin{tabular}{lccc}
\hline & Control & Hyperthyroid & Omega-3 treated \\
\hline ALT (U/L) & $59.13 \pm 7.56$ & $135.70 \pm 15.33^{*}$ & $62.77 \pm 9.26 \#$ \\
AST (U/L) & $131.09 \pm 20.51$ & $253.66 \pm 18.84^{*}$ & $136.24 \pm 17.60 \#$ \\
\hline
\end{tabular}

Note: Data are presented as means $\pm \mathrm{SD}(\mathrm{n}=8$ in each group).

* Statistically significant when compared to control group.

\# Statistically significant when compared to hyperthyroid group.

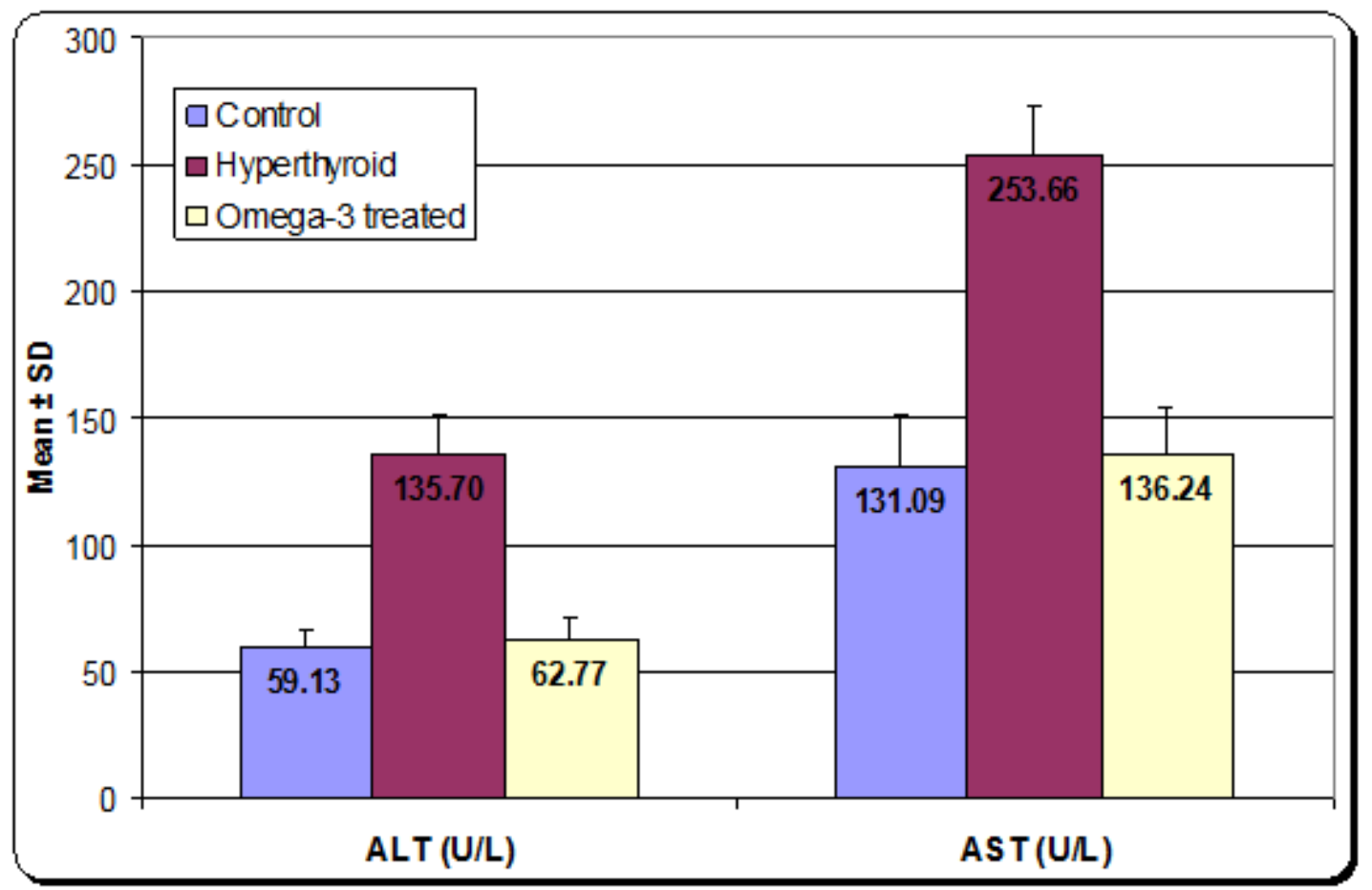

Histogram 3: Serum levels of ALT\&AST in different groups 
Table 3: Levels of collagen area $\%$ \& No. of CD68+ve cells and PCNA +ve cells/field in different groups

\begin{tabular}{|c|c|c|c|c|}
\hline & control & L thyroxine & $\begin{array}{c}\text { L.thyroxine }+ \text { Omega } 3 \\
\text { treated }\end{array}$ & P.value \\
\hline Collagen area $\%$ & $7.07 \pm .83$ & $20.36 \pm .65^{\mathrm{a}}$ & $10.05 \pm .72^{\mathrm{a}, \mathrm{b}}$ & .003 \\
\hline No. of CD68+ve cells & $5 \pm .83$ & $15 \pm 1,30^{\mathrm{a}}$ & $7 \pm 1.0^{\mathrm{a}, \mathrm{b}}$ & .002 \\
\hline No. of PCNA +ve cells & $99 \pm 7.2$ & $46 \pm 4.3^{\mathrm{a}}$ & $79 \pm 4.2^{\mathrm{a}, \mathrm{b}}$ & .000 \\
\hline
\end{tabular}

Statistical significant difference $(P<0.05)$

Mean \pm SD

a:Significant difference from control control

b. Significant difference from control and L.thyroxine treated group

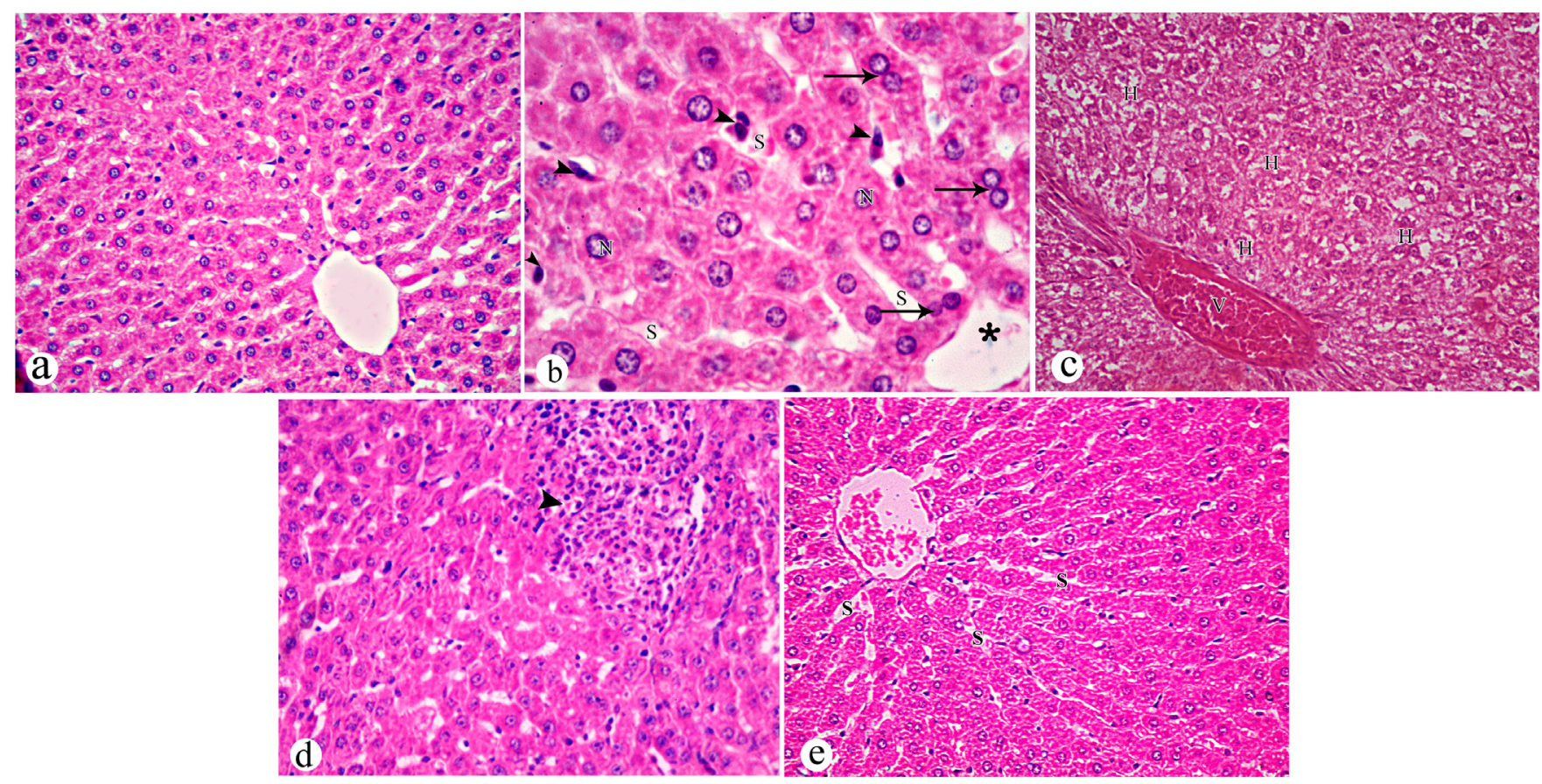

Fig. 1: Photomicrographs of liver sections (a) Control group; showing hepatocytes (H) radiating from the central vein H\&Ex 100. (b) Showing hepatocytes with e vesicular nuclei(N),some are binucleated $(\uparrow)$ separated with sinusoids(s), (*) central vein, H\&Ex400.(c) L.thyroxine treated group showing hepatocytes with vacuolated cytoplasm $(H)$, dilated blood vessel (V) H\&E x 100. (d) L.thyroxine treated group showing hepatocytes with patches of cellular infilteration(arrow head) H\&E x400 (e)L.thyroxine+omega3 treated group showing; regular arrangement of cellular cords, separated with blood sinusoids(s) H\&E x100 

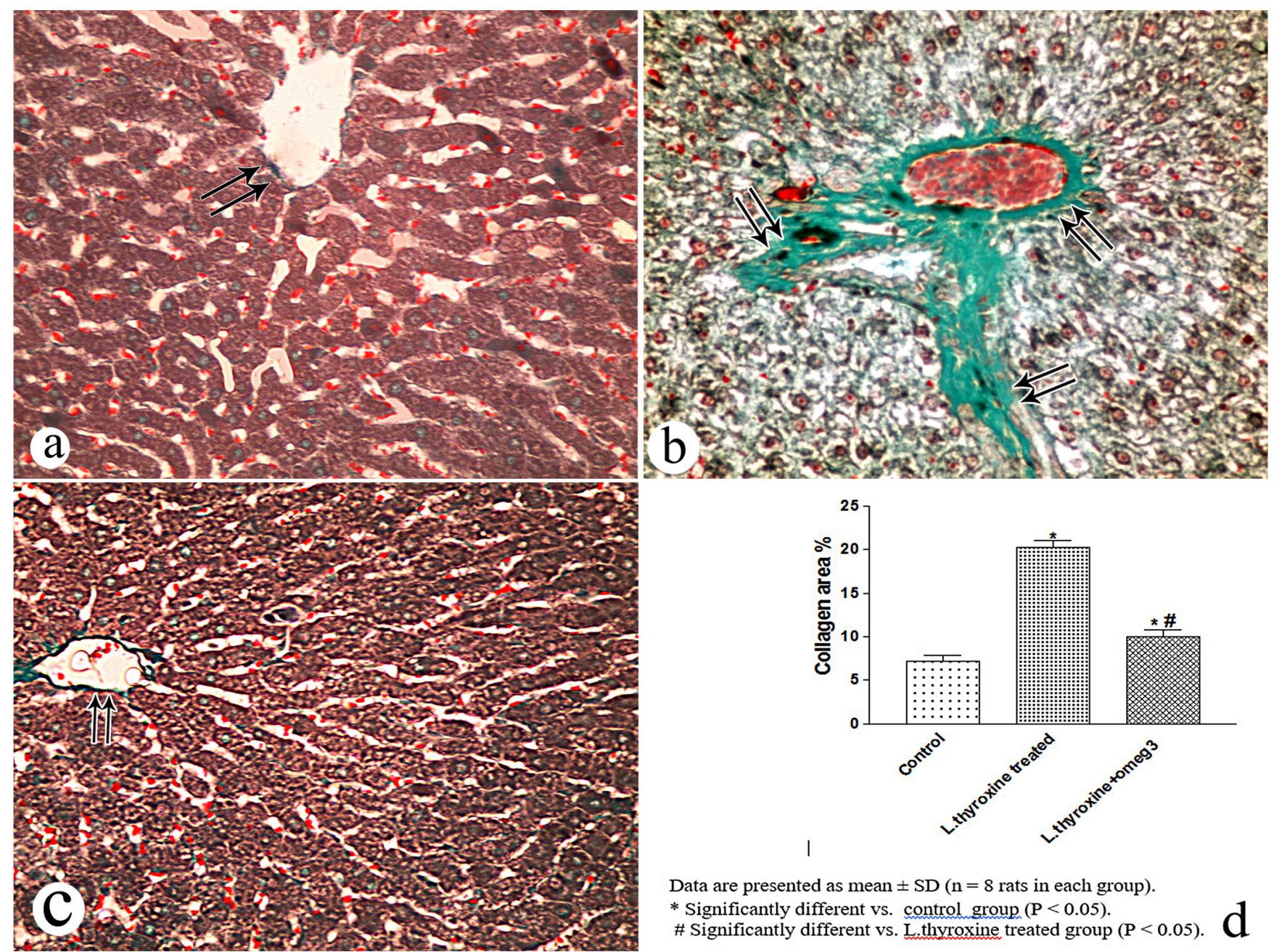

Fig. 2: Photomicrographs of liver sections(a) Control group showing: few collagen fibers around the central vein(double arrows). (b) L. thyroxine treated group showing: extensive amount of collagen fibers (double arrows). (c ) L.thyroxine+omega3 treated group showing few collagen fibers around the central vein(double arrows) Masson trichrome x100.(d)Collagen \% area showing statistically significant increase of collagen area in L. thyroxine treated group compared to control and significant decrease in omega 3 treated group compared to L. thyroxine treated group. 

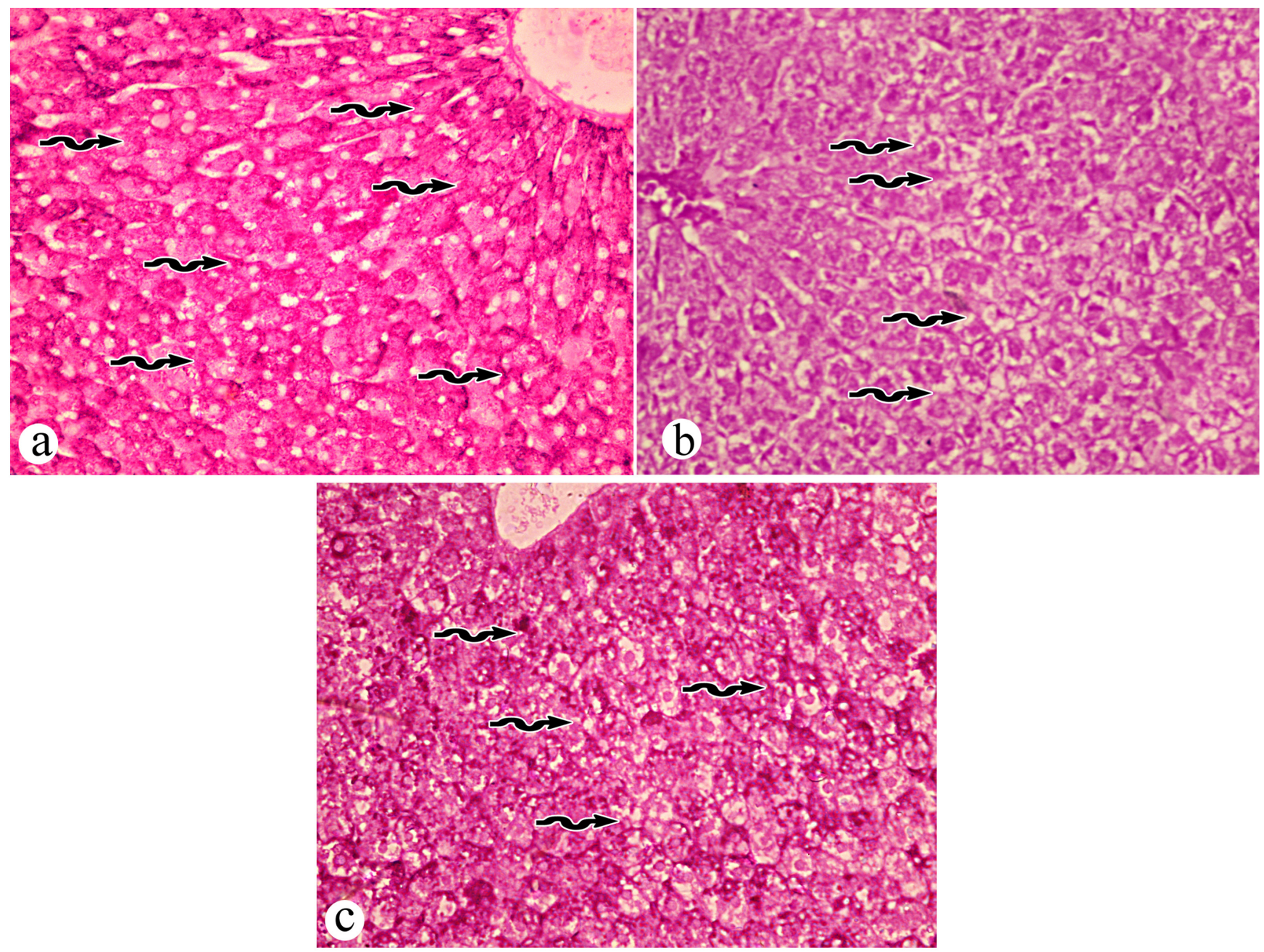

Fig. 3: Photomicrographs of liver sections (a) Control group showing: strong PAS reaction in most of hepatocytes ( wavy arrow)x100. (b) L. thyroxine treated group showing, weak PAS reaction in multiple hepatocytes (wavy arrow)x100. (c) L.thyroxine+omega3 treated group showing strong PAS reaction in multiple hepatocytes(wavy arrow) x100. 

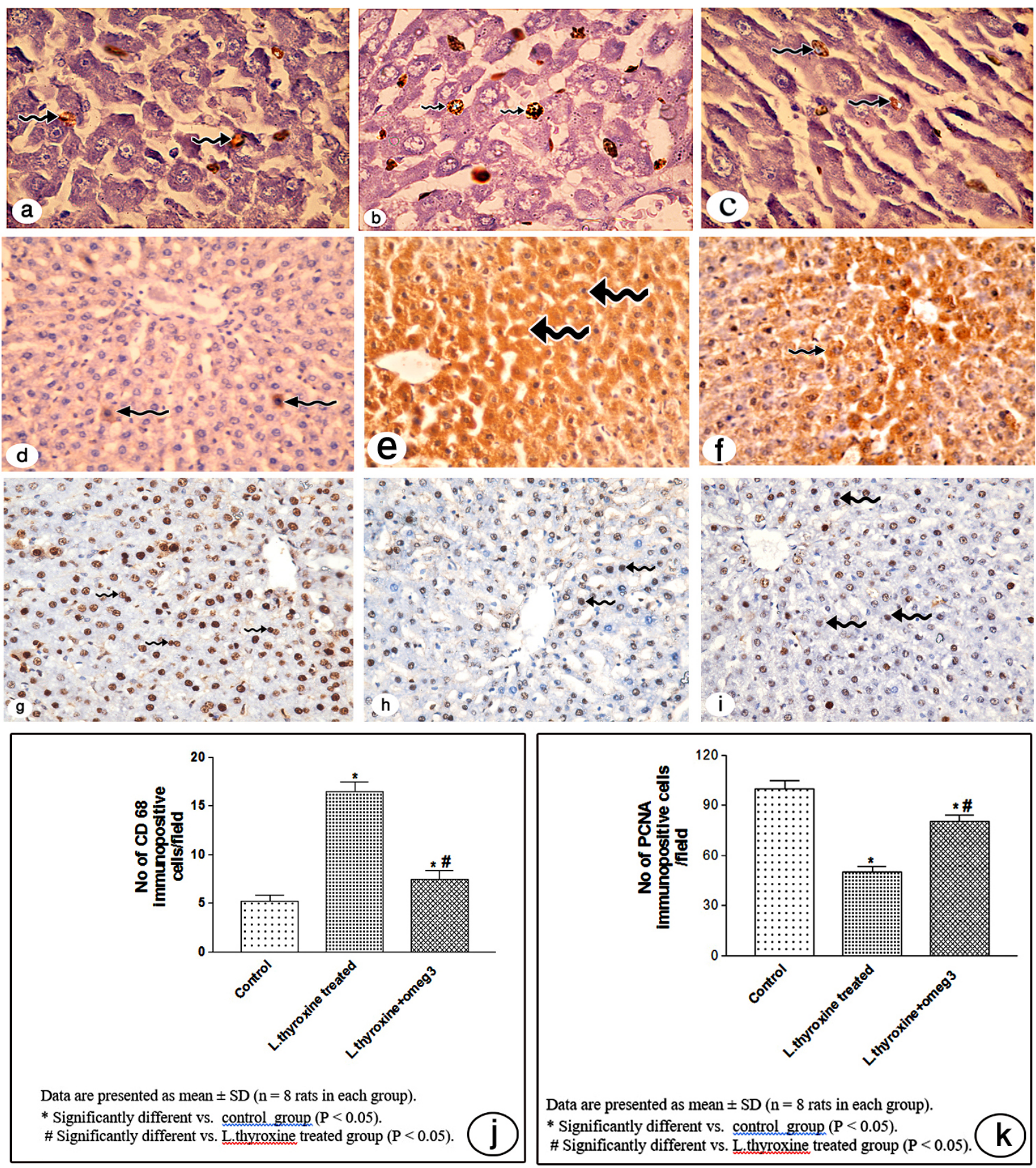

Data are presented as mean $\pm \mathrm{SD}(\mathrm{n}=8$ rats in each group)

* Significantly different vs. control group $(\mathrm{P}<0.05)$.

\# Significantly different vs. L.thyroxine treated group $(\mathrm{P}<0.05)$

Fig. 4: Immunohistochemical stained liver sections(a) Control group showing few CD68 +ve cells in the sinusoidal walls(wavy arrows). (b) L thyroxine treated group showing multiple scattered CD68 +ve cells (wavy arrows). (c) L. thyroxine + omega 3 treated group showing few CD68 +ve cells (wavy arrows)x 100. (d) Control group showing few caspase $3+v e$ cells in the hepatocytes (wavy arrow)x100. (e) L thyroxine treated group showing numerous caspase $3+v e$ cells(wavy arrows)x100.(f) L.thyroxine +omega3 treated group showing fewer caspase $3+$ ve cells (wavy arrows)x100.(g) Control group showing multiple PCNA +ve cells (wavy arrows)x100. (h) L.thyroxine treated group showing few PCNA +ve cells (wavy arrows) x100.(i) L.thyroxine+omeg3 treated group showing multiple PCNA +ve cells (wavy arrows)x100. (j) Showing significant difference increase number of CD68 + ve cells in L. thyroxine treared group compared to control and significant decrease of +ve cells in L-thyroxine +omega 3 treated group. (k) Showing significant decrease of number of PCNA +ve cells in L.thyroxine treated group compared to control and significant increase of $+\mathrm{ve}$ cells in L.thyroxine +omega3 treated group. 

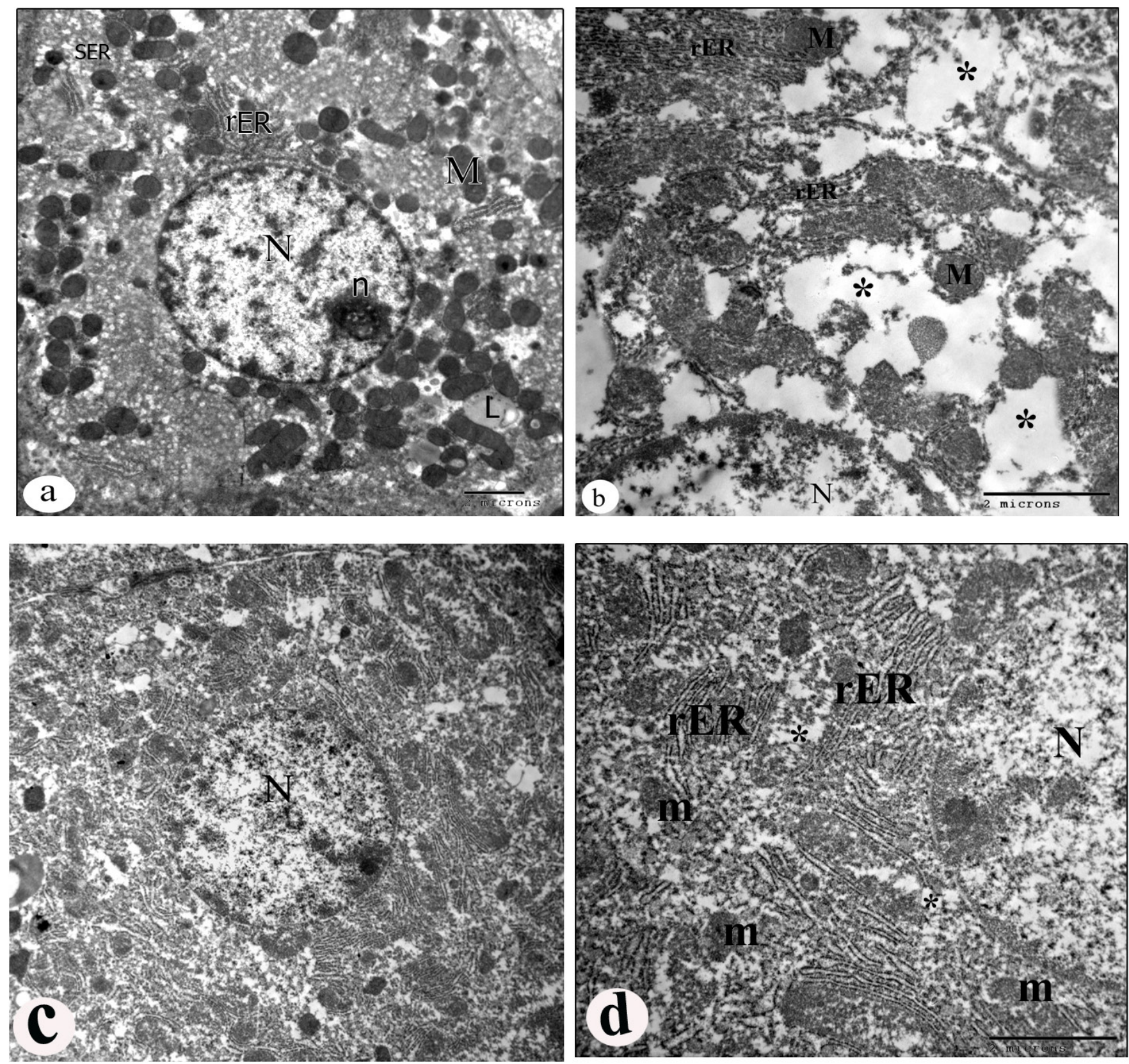

Fig. 5: Electron micrographs of liver sections(a) Control section showing large euchromatic nuclei(N) with prominent nucleoli. Numerous mitochondria(m), rER, SER and lipid droplets(L) can be seen x3600. (b) L.thyroxine treated section showing rarified cytoplasm with electron lucent areas $(*)$ and few mitochondria (m)x7200. (c) L-thyroxine +omega3 treated group showing nucleus (N)with more condensed chromatin $(*) \times 3600$. (d) Showing apparently normal (rER) and mitochondria(m) x7200.

\section{DISCUSSION}

Thyroid hormones have an important implication on the liver structure and functions so serious liver changes resulted from imbalance of the thyroid hormones either in hyperthyroid or hypothyroid states ${ }^{[25]}$. In the present study, we investigated the effects of omega3 fatty acids on Lthyroxine induced hyperthyroidism and subsequent altered liver histological changes with their possible antioxidant effects in a dose $3 \mathrm{~g} / \mathrm{kg} /$ day.

In the present work, administration of L-thyroxine intraperitoneally for six weeks led to histological liver changes. Light microscopic examination showed disorganized hepatic architecture with degeneration in the hepatocytes, vascular dilatation, congestion, and mononuclear cell infiltration. Ultra structurally; the cytoplasm of the hepatocytes contained multiple cytoplasmic vacuoles or cytoplasmic rarefaction. These findings were in agreement with some studies which examined the relation between thyroid and liver diseases ${ }^{[26]}$

Observed multiple vacuoles in the cytoplasm of the hepatocytes could be explained accumulation of toxic 
metabolites which caused damage of the cell membrane which led to hydropic degeneration . The protein content was watered down and the cell was less stained ${ }^{[27]}$.

In a previous study, inflammatory cellular infiltrations were exhibited between hepatocytes due to movement of fluids and leukocytes from the blood into the extravascular tissue as a reaction of microcirculation in inflammatory conditions. High levels of prostaglandins (PGs) synthesis that induces smooth muscle relaxation with subsequent sinusoidal dilatation, while congestion might be due to loss of fluid from the blood and the vessels got engorged with $\mathrm{RBCs}^{[28]}$.

Intense production of reactive oxygen species (ROS) and reactive nitrogen species (RNS), leading to the condition of oxidative stress which is involved in the pathogenesis of many human diseases might attributed to thyroid hormones (THs) that stimulate the metabolism of cells and tissues, regulating the consumption of oxygen. However, and increasing aerobic metabolism in mitochondria ${ }^{[29]}$. ROS induces damage on proteins, membrane lipids, and DNA.

Our results showed significant elevation of the thyroid hormones that stimulate the metabolism of cells and tissues and subsequent hepatic glycogenlysis ${ }^{[30]}$ resulting in reduction in the glycogen content of hepatocytes. Also significant increase in the collagen deposition was also observed after induction of hyperthyroidism as receptors of THs in the liver were reported to have a role in liver fibrogenesis. Excess T3 enhanced transforming growth factor (TGF) - induced collagen I gene expression which explained regression of hepatic fibrosis in Hypothyroid state ${ }^{[31]}$. Another explanation of increase liver fibrosis might result also from activation of stellate cells by ROS with subsequent increased collagen synthesis and fibrogenesis ${ }^{[32]}$.

Significant increase in the CD68+ve cells were observed after administration of L-thyroxine compared to control. Similarly ${ }^{[33]}$ cited that Phagocytic cells of the liver, the von Kupffer cells were affected by thyroxyine which were activated or their density increased by both foreign and natural substances. Also hepatocytes are being degraded at a higher rate in the thyroxine treated livers than in the control group. There was a close association between Fibrosis and increased Kupffer cells, in which fibrogenic and inflammarory mediators stimulated Kupffer cells with subsequent stellate cells activation and apoptosis of hepatocytes ${ }^{[34]}$.

Increased ROS accompanied with an enhanced inflammatory response may be the cause of the histological distortion of hepatic architecture. The increased proinflammatory mediators led to hepatocytic cell death pathways through caspase activation which in agreement with Assaei R. etal 2014 ${ }^{[35]}$. This suggestion was proved in our study by significant increase in caspase 3 expression in hyperthyroid rats compared to control. Moreover, excess THs has been found to activate the production of TNF- andIL-1_ led to increased defensive responses in parenchymal cells with activation of apoptosis. But these defensive responses could result in decreased cellular proliferation and death of cells by necrosis which was observed in our study by significant decrease in PCNA immunostained cells compared to control which indicates severe liver degeneration.

Our liver histological changes due to hyperthyroidism was documented by significant increase in the liver enzymes ALT and AST serum levels in hyperthyroid animals compared to control which indicated altered liver changes. Also,the important sign for improvement of altered liver changes after treatment with omega3 was the significant decrease of liver enzymes. Improvement of ALT and AST serum levels was an indicator about regression of cellular and tissue degeneration ${ }^{[36]}$.

Our histological results revealed that most of hepatocytes were regenerated and apparently normal after addition of omega3. As omega-3 fatty acids was reported that are enriched in EPA and DHA which have anti-inflammatory, antioxidant, antiapoptotic effects and regulate cell death ${ }^{[37]}$

Omega3 fatty acids performed a hepatoprotective effect through incorporation to cell membranes of all tissues and affected the important cellular functions as modulation of inflammation and synthesis of signaling molecules related to cell growth. Also they were reported to activate endogenous defense mechanisms and accelerate regeneration injured organelles specially mitochondria ${ }^{[38-39]}$.

In the present study significant reduction of collagen deposition was observed after administration of omega compared to control. The ability of omega- 3 to increase glycogen con-tent and decrease fibrous tissue might be caused by the associated decrease in the level of THs.

Zeng, yang et al. 2017 $7^{[40]}$ cited that omega3 can suppress TGF $\beta 1$-induced fibroblast activation at a dose and time dependent manner. Additionally ${ }^{[41]}$ revealed that omega -3 PUFAs down-regulate the expression of profibrogenic genes in activated HSCs(hepatic stellate cells) and fibrotic liver. This antifibrotic activity proved through inducing degradation of their transcriptional regulator; Yes-associated protein (YAP) in a proteasome dependent manner.

Liver improvement could be explained by the ability of omega 3 fatty acids to attenuate oxidative stress and regulation of inflammatory pathways as omega-3 was considered as an important precursor for resolvins and protectins which are lipid-derived modulators of cell inflammatory processes. Resolvin and protectins are very important factors for regulation the number and activity 
of Kupffer cells as they stimulate macrophage switching from the pro-inflammatory M1 phenotype to the antiinflammatory M2 phenotype. So Macrophages have a role both in liver fibrogenesis and fibrinolysis by acquiring different phenotypes ${ }^{[42]}$.

Our study demonstrated significant decrease in the immunostained caspase 3 positive cells after treatment with omega3. Similarly, Sinha,Khare etal.2009 ${ }^{[43]}$ attributed the antiapoptotic effect of omega 3 on mitochondrial pathway via maintaining the anti-apoptotic balance of Bcl-2 family proteins in degenerating neurons in perinatal hypothyroidism model

In addition Cetrullo,Tantini.etal 2012 $2^{[44]}$ arrtibuted the antiapoptotic effect of omega3 fatty acids due to their to counteract the main biochemical markers of apoptosis such as the activation of caspases and the DNA fragmentation.

A significant increase in PCNA expression in hepatocytes nuclei after concomitant treatement with omega3 fatty acid which can explain by their antioxidant role. Simmilarly Uygur,Aktas et al. 2014 $4^{[45]}$ found increased PCNA in rat testis following treatement with omega-3 fatty acids due to decreased doxorubicin-induced oxidative damage.

Conclusion: From the previous obtained anti-oxidant, anti-inflammatory, anti-apoptotic and proliferating activities of omega3 fatty acids we can conclude that the omega- 3 fatty acids may ameliorate $\mathrm{L}$ thyroxine overdose. So; the nutrient content of a diet may improve the potential negative effect of hyperthyroidism. Also they were considered an important hepatoprotective supplementation agents to hyperthyroid patients.

\section{CONFLICT OF INTEREST}

There is no conflict of interest

\section{REFERENCES}

1. Horton, J., J. Goldstein, and M. Brown. SREBPs: transcriptional mediators of lipid homeostasis. in Cold Spring Harbor symposia on quantitative biology. 2002. Cold Spring Harbor Laboratory Press ;67: p.491-8

2. Lin, J. Yang R, Tarr PT, Wu PH, Handschin C, Li S, Yang W, Pei L, Uldry M, Tontonoz P, Newgard CB, Spiegelman BM., Hyperlipidemic effects of dietary saturated fats mediated through PGC-1 $\beta$ coactivation of SREBP. Cell, 2005. 120(2): p. 261273.

3. Fagiuoli, S. and Van Thiel, D.H. The liver in endocrine disorders. The liver in systemic disease, 1993: p. 285-301.
4. Khan, T.M., S. Malik, and I.U. Diju, Correlation between plasma thyroid hormones and liver enzymes level in thyrotoxic cases and controls in Hazara Division. Journal of Ayub Medical College Abbottabad, 2010. 22(2): p. 176-179.

5. Soukup, T., Effects of long-term thyroid hormone level alterations, n-3 polyunsaturated fatty acid supplementation and statin administration in rats. Physiological research, 2014. 63 (1):p 119-31.

6. Majima, T. Komatsu Y, Doi K, Takagi C, Shigemoto M, Fukao A, Morimoto T, Corners J, Nakao K. Clinical significance of risedronate for osteoporosis in the initial treatment of male patients with Graves' disease. Journal of bone and mineral metabolism, 2006. 24(2): p. 105-113.

7. Luo, H., Li, X., Xiao, S., Zhang, X,.Effect of Shenmaisanjie capsules on hyperthyroidisminduced liver damage in rat. Int J Clin Exp Med, 2017. 10(8): p. 11903-11911.

8. Huang, L., Heinloth, A.H., Zeng,Z. B., Paules., R. H.Genes related to apoptosis predict necrosis of the liver as a phenotype observed in rats exposed to a compendium of hepatotoxicants. BMC genomics, 2008. 9(1): p. 288.

9. Elias, R.M., Dean, D.S. and Barsness, G.W. , Hepatic dysfunction in hospitalized patients with acute thyrotoxicosis: a decade of experience. ISRN endocrinology, 2012. 2012.

10. Venditti, P. and Meo, S. Di., Thyroid hormoneinduced oxidative stress. Cellular and Molecular Life Sciences CMLS, 2006. 63(4): p. 414-434.

11. Subudhi, U. and Chainy, G.B., Expression of hepatic antioxidant genes in 1-thyroxine-induced hyperthyroid rats: regulation by vitamin $\mathrm{E}$ and curcumin. Chemicobiological interactions, 2010. 183(2): p. 304-316.

12. Subudhi, U., , Das K, Paital B, Bhanja S, Chainy GB., Alleviation of enhanced oxidative stress and oxygen consumption of L-thyroxine induced hyperthyroid rat liver mitochondria by vitamin $\mathrm{E}$ and curcumin. Chemico-Biological Interactions, 2008. 173(2): p. 105-114.

13. Friedman, A. and Moe, S., Review of the effects of omega-3 supplementation in dialysis patients. Clinical Journal of the American Society of Nephrology, 2006. 1(2): p. 182-192.

14. Namiki, M., Nutraceutical functions of sesame: a review. Critical reviews in food science and nutrition, 2007. 47(7): p. 651-673. 
15. Whelan, J. and Rust, C. Innovative dietary sources of n-3 fatty acids. Annu. Rev. Nutr., 2006. 26: p. 75-103.

16. da Silva, E., Nachbar, R. T., Levada-Pires, A. C. . Hirabara, S. M. and Lambertucci, R. H. Omega-3 fatty acids differentially modulate enzymatic antioxidant systems in skeletal muscle cells. Cell Stress and Chaperones, 2016. 21(1): p. 87-95.

17. Hu, F.B., , Meir J. ,JoAnn, E., , Graham, A. Walter, C.,. Dietary fat intake and the risk of coronary heart disease in women. New England Journal of Medicine, 1997. 337(21): p. 1491-1499.

18. Simopoulos, A.P., Omega-3 fatty acids in inflammation and autoimmune diseases. Journal of the American College of nutrition, 2002. 21(6): p. 495-505.

19. Kobori, H., Ichihra, A., Suzuki, H., Takenaka, T., Hayashi, M., Role of the renin-angiotensin system in cardiac hypertrophy induced in rats by hyperthyroidism. American Journal of PhysiologyHeart and Circulatory Physiology, 1997. 273(2): p. H593-H599.

20. Ferraz, A.C., Delattre AM, Almendra RG, Sonagli M, Borges C, Araujo P, Andersen ML, Tufik S, Lima MM., Chronic $\omega-3$ fatty acids supplementation promotes beneficial effects on anxiety, cognitive and depressive-like behaviors in rats subjected to a restraint stress protocol. Behavioural brain research, 2011. 219(1): p. 116-122.

21. M, B.J.a.G., Theory and practice of histological techniques.6th ed. Scotland, London: Churchill Livingstone,p75-110 2008.

22. MA, H., ed. Principles and techniques of electron microscopy: biological applications. 4th ed. Edinburgh, UK: Cambridge University Press.p.106, 2000.

23. Baratta, J.L., Ngo A, Lopez B, Kasabwalla N, Longmuir KJ, Robertson RT., Cellular organization of normal mouse liver: a histological, quantitative immunocytochemical, and fine structural analysis. Histochemistry and cell biology, 2009. 131(6): p. 713-726.

24. Garth, A. Analysing data using SPSS. Sheffield Hallam University,2008,p 2-91.

25. Das, K. and Chainy, G. Modulation of rat liver mitochondrial antioxidant defence system by thyroid hormone. Biochimica et Biophysica Acta (BBA)Molecular Basis of Disease, 2001. 1537(1): p. 1-13.
26. Chung, Y.-H., Jung, SA., Song, BC., Chang, WY., Kim, JA., Song, IH., Kim, JW., Choi. WB., Shong, YK., .Plasma isocitrate dehydrogenase as a marker of centrilobular hepatic necrosis in patients with hyperthyroidism. Journal of clinical gastroenterology, 2001. 33(2): p. 118-122.

27. Walter JB, I.M., Inflammation. In:Walter JB, Talbot JC, editors. Walter general pathology.7th ed. New York: Churchill Livingstone,p. 1671996.

28. E, R., Essential pathology. . 3rd ed. P.85-88,2001 Lippincott William \& Wilkins.

29. Messarah, M., Boumendjel, A.,Chouabia, A., Influence of thyroid dysfunction on liver lipid peroxidation and antioxidant status in experimental rats. Experimental and Toxicologic Pathology, 2010. 62(3): p. 301-310.

30. Chandra, A.K., Sinha, S. and Choudhury, S.R. Thyroxine induced stress and its possible prevention by catechin. 2010. 48(6):p.559-65.

31. Geraci, J. and Mariano, M., Radiation hepatology of the rat: parenchymal and nonparenchymal cell injury. Radiation research, 1993. 136(2): p. 205 213.

32. Safadi, R. and Friedman, S. Hepatic fibrosis--role of hepatic stellate cell activation. MedGenMed Medscape general medicine, 2002. 4(3): p. 27-37.

33. Taylor, C., EFFECTS OF THYROXINE ON LIVER STRUCTURE OF XENOPUS LAEVIS. 2007:p1-28.

34. Beljaars, L., Schippers, M., Reker-Smit, C., Martinez, FO., , Helming, L., Hepatic localization of macrophage phenotypes during fibrogenesis and resolution of fibrosis in mice and humans. Frontiers in immunology, 2014. 5: p. 430.

35. Assaei, R., h., Zal, F., Zohreh Mostafavi-Pour, Z., Mohammad Hossein Dabbaghmanesh, M.H., Hepatoprotective effect of Satureja Khuzestanica essential oil and vitamin $\mathrm{E}$ in experimental hyperthyroid rats: Evidence for role of antioxidant effect. Iranian journal of medical sciences, 2014. 39(5): p. 459.

36. Rajasekaran, S., Ravi, K., Sivagnanam, K., Subramanian, S., Beneficial effects of Aloe vera leaf gel extract on lipid profile status in rats with streptozotocin diabetes. Clinical and Experimental Pharmacology and Physiology, 2006. 33(3): p. 232-237. 
37. Schm $\square$ ocker, C., Kahlke, L., Wang, J., Lobeck, H., Tiegs, G., Berg, T., Omega-3 Fatty Acids Alleviate Chemically Induced Acute Hepatitis by Suppression of Cytokines. HEPATOLOGY, 2007. 45(4):p 864-9.

38. Khan, M., Priyamvada, S., Khan, SA., Protective effect of $\omega-3$ polyunsaturated fatty acids (PUFAs) on sodium nitroprusside-induced nephrotoxicity and oxidative damage in rat kidney. Human \& experimental toxicology, 2012. 31(10): p. 10351049.

39. Guixà-González, R., Javanainen, M., GómezSoler, M., Cordobilla, B.,, Carles, J., Membrane omega-3 fatty acids modulate the oligomerisation kinetics of adenosine A 2A and dopamine D 2 receptors. Scientific reports, 2016. 6: p. 19839.

40. Zeng, Z., Yang, H., Wang, Y., Ren, J., Y., Dai, C., Omega-3 Polyunsaturated Fatty Acids Attenuate Fibroblast Activation and Kidney Fibrosis Involving MTORC2 Signaling Suppression. Scientific reports, 2017. 7: p. 46146.

41. Zhang, K., Chang, Y.,, Shi, Z.,, Han, X.,, Han, Y., $\omega-3$ PUFAs ameliorate liver fibrosis and inhibit hepatic stellate cells proliferation and activation by promoting YAP/TAZ degradation. Scientific reports, 2016. 6: p. 30029.
42. Fallowfield, J.A., Mizuno, M., Kendall, TJ., Constandinou, CM., Benyon, RC., Duffield, JS., Iredale, JP., Scar-associated macrophages are a major source of hepatic matrix metalloproteinase- 13 and facilitate the resolution of murine hepatic fibrosis. The Journal of Immunology, 2007. 178(8): p. 5288-5295.

43. Sinha, R.A., hare, P., Rai, A., Maurya, SK., Pathak ,A., Mohan, V., Naga, GK., Mudiam, MK.,Anti-apoptotic role of omega-3-fatty acids in developing brain: perinatal hypothyroid rat cerebellum as apoptotic model. International Journal of Developmental Neuroscience, 2009. 27(4): p. 377-383.

44. Cetrullo, S., ,B., Flamigni, F., Pazzini, C., Facchin, A., Antiapoptotic and antiautophagic effects of eicosapentaenoic acid in cardiac myoblasts exposed to palmitic acid. Nutrients, 2012. 4(2): p. 78-90.

45. Uygur, R., Aktas, C., A.,Tulubas, F., Uygur, E., Kanter, M., Erboga, M., Caglar, V. ,Protective effects of fish omega-3 fatty acids on doxorubicininduced testicular apoptosis and oxidative damage in rats. Andrologia, 2014. 46(8): p. 917-926. 
الملخص العربى

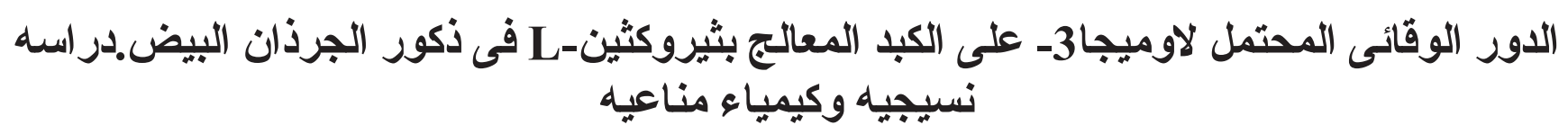

فاطمة يس عبدالمتجلى مليجى' , علا عبدالتواب حسين' , هبه علاء الدين مبارك' و محمد

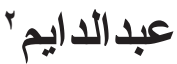

' قسم الههتولوجى وبييولوجيا الخليه كلية الطب جامعة اسيوط اسيوط

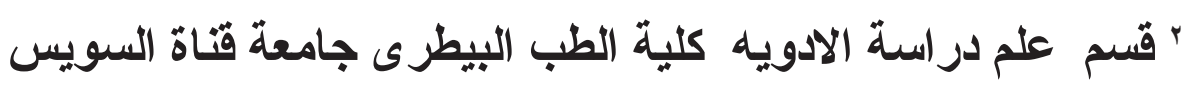

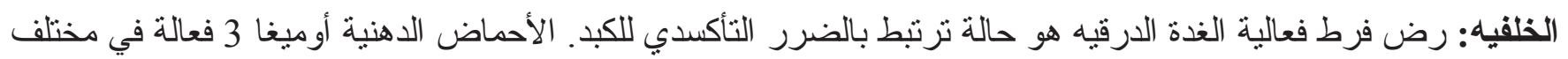

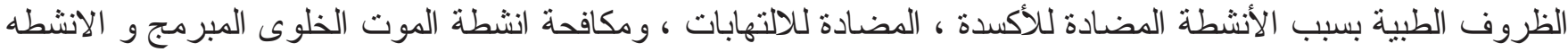
التلافيه.

الهـف من البحث: نحن هنا نقييم الآثار المحتملة للأحماض الدهنية أوميغا 3 على فرط نشاط الغدة الدرقية المستحثة تجريبيا.

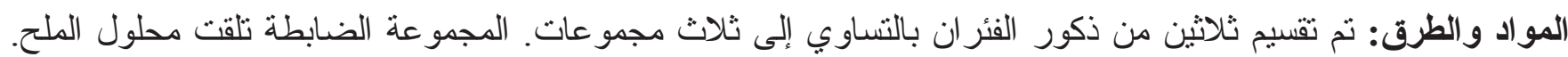

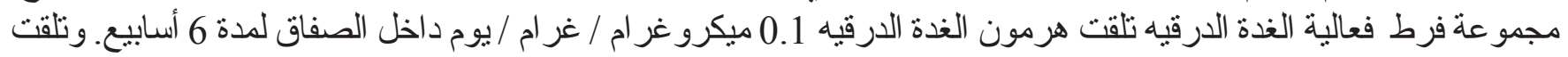

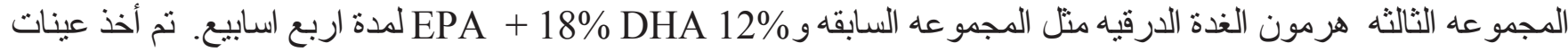

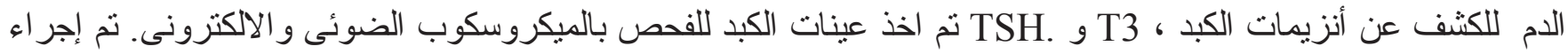

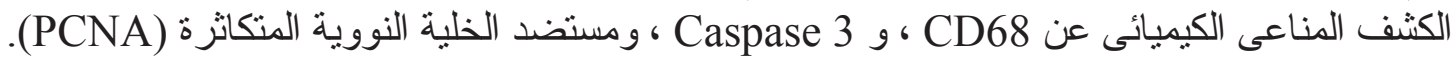

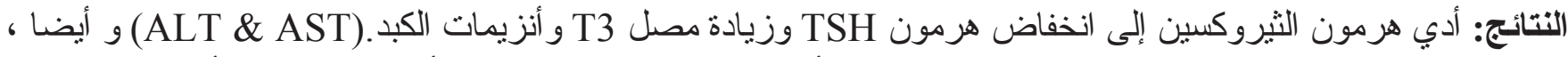

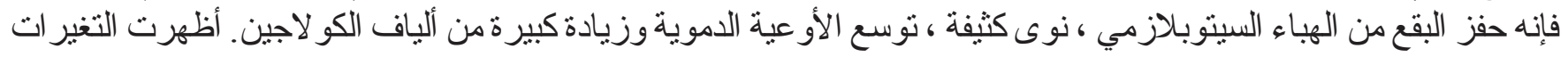

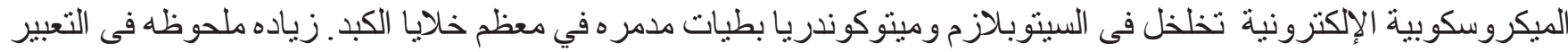



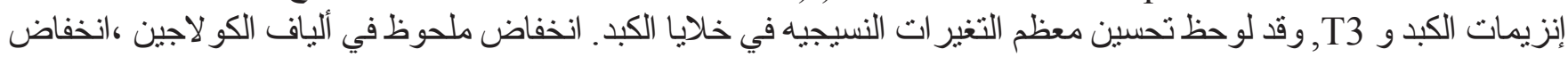

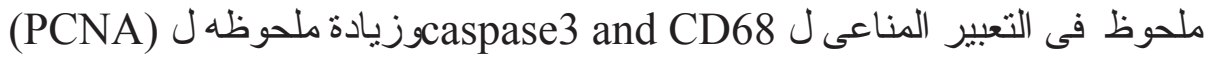
الخلاصه: تز امن العلاج با لأحماض الدهنية (أوميغا 3) حسن الكثير من التغير ات التى نتجت من استخدام هرمون الغده الدرقيه. 